\title{
PKM UNTUK PEMANFAATAN SISTEM INFORMASI PANORAMA VIEW 360 BERBASIS WEB DAN SOSIAL MEDIA SEBAGAI SARANA PROMOSI PARIWISATA BAGI PEBISNIS PARIWISATA DI TORAJA
}

\author{
Andrea Stevens Karnyoto ${ }^{1}$, Parea Rusan Rangan ${ }^{2}$ \\ ${ }^{1}$ Program Studi Teknik Informatika \\ ${ }^{2}$ Program Studi Teknik Sipil \\ Fakultas Teknik \\ Universitas Kristen Indonesia Toraja
}

\begin{abstract}
ABSTRAK
Kabupaten Tana Toraja dan Toraja Utara memiliki puluhan tempat wisata, menurut data dari dinas pariwisata kedua kabupaten tersebut terdapat 42 tempat wisata yang telah terdaftar. Beberapa website sudah memuat ulasan tentang beberapa tempat wisata tetapi belum ada yang menampilkan pemandangan panorama ?, pemandangan panorama memberikan kesan menarik pada suatu tempat karena pengunjung dapat melihat dari satu titik kesekeliling tanpa batas. Teknologi ini dapat diakses baik menggunakan komputer maupun mobile. Dalam website tersebut juga akan ditampilkan posisi GPS (Global Position System) masing-masing tempat wisata. Oleh karena banyaknya tempat wisata di Toraja dan adanya teknologi panorama maka pengabdi melihat kesempatan untuk bekerja sama dengan mitra dalam hal promosi usaha pemandu wisata dan usaha perjalanan yang dimiliki oleh dua mitra. Promosi muktahir ini diharapkan dapat meningkatkan pendapatan mitra. Pengabdi memberikan media promosi berupa website kepada mitra, memberikan kamera yang mampu melakukan pengambilan gambar secara panorama, memberikan pendampingan berupa pelatihan pengelolaan website, pelatihan pemanfaatan sosial media sebagai sarana promosi serta cara menggunakan komunikasi interaktif dengan pengunjung website atau wisatawan. Keuntungan tidak hanya diperoleh mitra karena mendapatkan media promosi dan pelatihan peningkatan SDM, tetapi juga keuntungan untuk para pengujung website karena dapat melihat tempat wisata di Toraja secara panorama dan menyeluruh.
\end{abstract}

Keyword : Pemandangan Panorama, Website Interaktif, Wisatawan.

\section{PENDAHULUAN}

Kabupaten Tana Toraja dan Toraja Utara memiliki puluhan tempat wisata, menurut data dari dinas pariwisata kedua kabupaten tersebut terdapat 42 tempat wisata yang telah terdaftar, masih terdapat juga tempat wisata yang belum terdaftar dan belum direkomendasikan karena kondisi prasarana yang belum memadai. Tempat wisata dibagi menjadi dua, tempat wisata adat dan tempat wisata alam. Pariwisata sudah menjadi lahan bisnis bagi beberapa bidang usaha, mulai dari penyedia layanan pemandu wisata, pembuat dan penjual kerajinan tangan, jasa angkutan dan lain sebagainya. Potensi promosi bisnis pariwisata ini yang akan ditingkatkan oleh pengabdi dan dua mitra yang akan bekerja sama untuk melakukan PKM. 
Dua mitra yang diusulkanoleh pengabdi dalam dalamPKMiniadalah jasa layanan Pemandu Wisatayang bekerja secara berkelompok dan layanan transportasi wisata.

\section{TARGET LUARAN}

\subsection{Solusi-solusi yang Ditawarkan}

Merujuk pada permasalahan mitra pada bagian 1.2 proposal ini, maka solusi yang harus dilakukan adalah sebagai berikut:

- Pembuatan Website Sebagai Media Promosi yang Menarik Menggunakan Panorama 360

- Melakukan Pelatihan Pengembangan Media Promosi (Website)

- Melakukan Pelatihan Menggunakan Sosial Media sebagai Sarana Promosi

Tahapan Pelaksanaan Pengabdian

Tahapan pengabdian dirancang untuk menyelesaikan dua permasalahan mitra yaitu bidang manajemen dan promosi guna meningkatkan pendapatan dan efisiensi serta memaksimalkan pendapatan mitra. Tahapan-tahapan ini melibatkan pengabdi, kedua mitra dan mahasiswa, tahapan terdiri dari:

1) Survei dan MengumpulkanInformasi

Tahapan ini pengabdi mengumpulkan informasi internal yang dapat dijadikan bahan promosi pada website dan mencari cara kerja manajemen mitra.

2) Melakukan Desain Website dan Pengajuan Manajemen

Desain website panorama ? dilakukan bersama dengan mitra, mitra memberikan masukan informasiinformasi yang menjadi fundamental dan pengabdi mengamati sertai memberikan solusi yang paling tepat. Dalam bidang manajemen pengabdi mempelajari manajemen dari perusahaan yang telah sukses dan coba diaplikasikan pada sistem website.

3) Pembuatan Website panorama ?

Tahapan ini pengabdi mengembangkan website dimulai dengan membuat seluruh halaman lalu mendaftarkan domain serta melakukan hosting. Untuk data-data tempat wisata, dilakukan oleh pengabdi bekerjasama dengan mahasiswa untuk mengambil gambar panorama ?].

4) Pelatihan Pengelolaan Website dan Pemanfaatan Sosial Media

Pelatihan sangat diperlukan guna melakukan transfer pengetahuan, pelatihan akan dibagi menjadi tiga yaitu: 1)Pengelolaan Website, 2)Menjalankan manajemen yang telah disepakati dan telah diimplementasikan dalam sistem website, 3)Pemanfaatan Sosial Media seperti Facebook, Twitter dan Path. 


\section{Proses Penggunaan Kamera Kogan 360, Panellum, dan Free Hugin}

Telah disebutkan sebelumnya bahwa pengambilan gambar dilakukan sebanyak 3 kali dari sudut yang berbeda-beda. Yaitu $360^{\circ} / 3=120^{\circ}$, jadi pengambilan gambar harus dilakukan dengan mensejajarkan belakang kamera terhadap kaki-kaki dari tripot. Hasil yang didapat dapat dilihat seperti berikut.

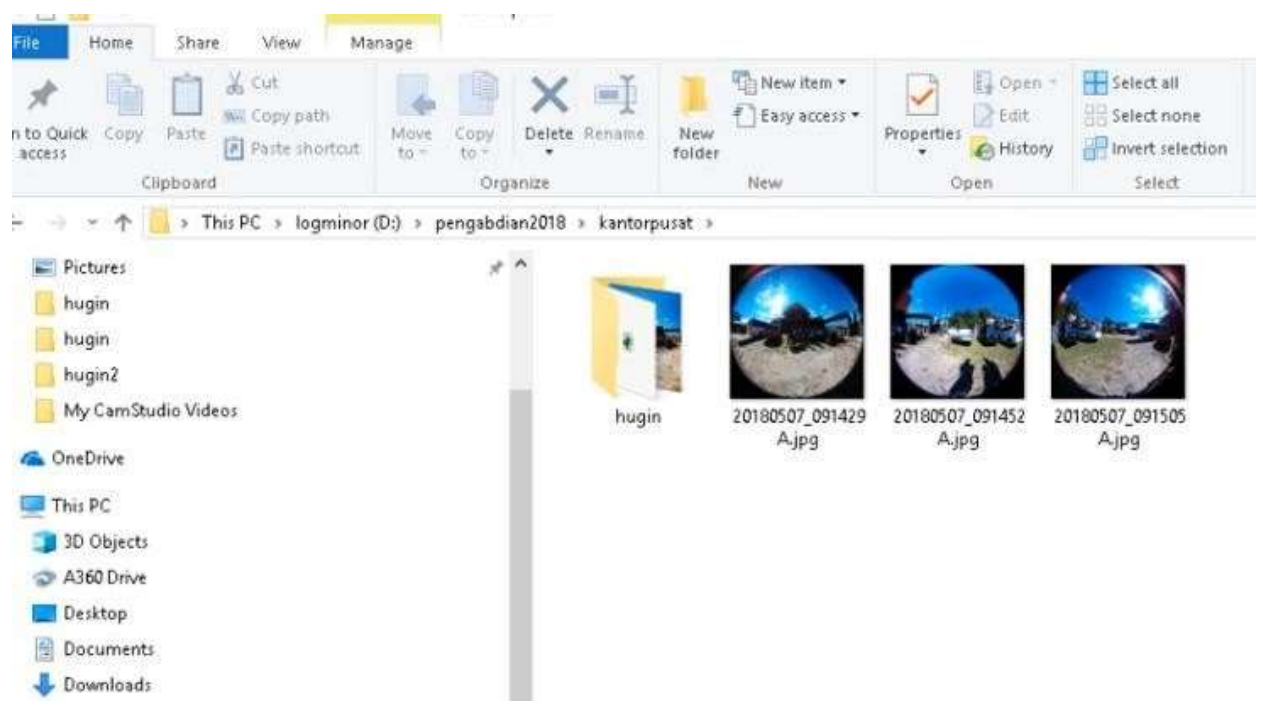

Gambar 1. Berkas gambar hasil pengambilan gambar dari kamera Kogan 360

Pada gambar 1 dilihat bahwa gambar yang didapat merupakan gambar dengan sudut pengambilan gambar $220^{\circ}$ sehingga terlihat lebih luas dibandingkan dengan kamera biasa. Tiga berkas tersebut sebelum disatukan harus dilakukan pemotongan(crop) pada kiri dan kanan gambar menggunakanperangkatlunakphotoshop sepertiyangterlihatpada gambar 5.8. 


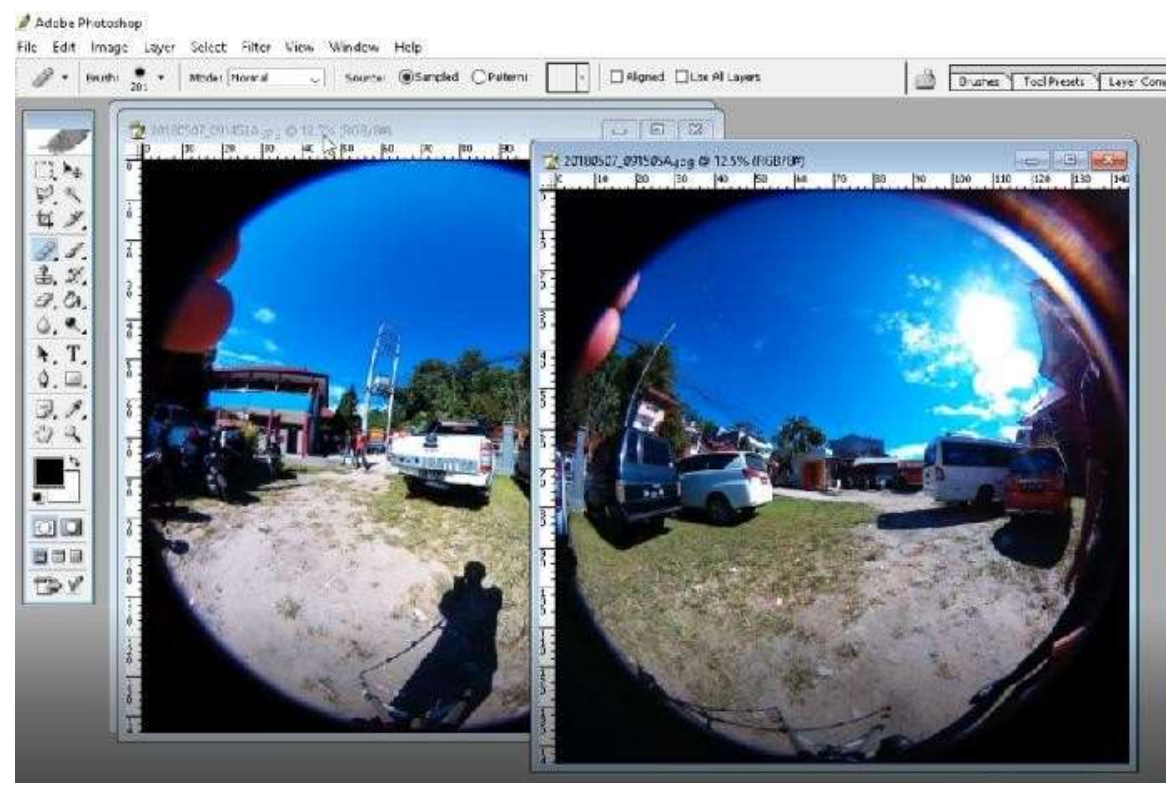

Gambar 2 Gambar dari kamera kogan yang dimasukkan pada perangkat lunak photoshop

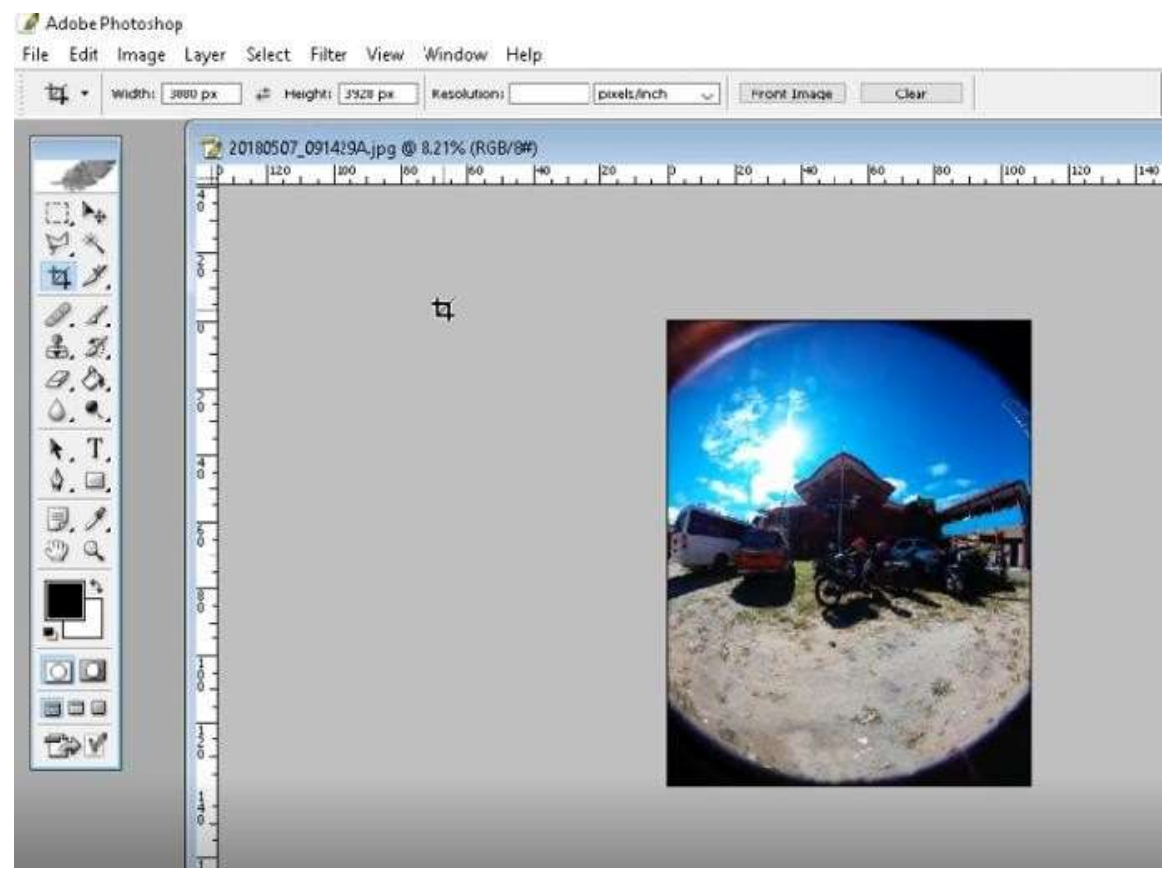

Gambar 3. Gambar dari kamera kogan yang telah di crop dengan ukuran tertentu

Pada gambar 3 dapat dilihat bahwa gambar yang dihasilkan kogan harus di crop dengan ukuran 3080px X 3928 px. Hasil dari crop tersebut disimpan kembali dan diorganisasikan berdasarkan kelompok-kelompok gambarnya. 


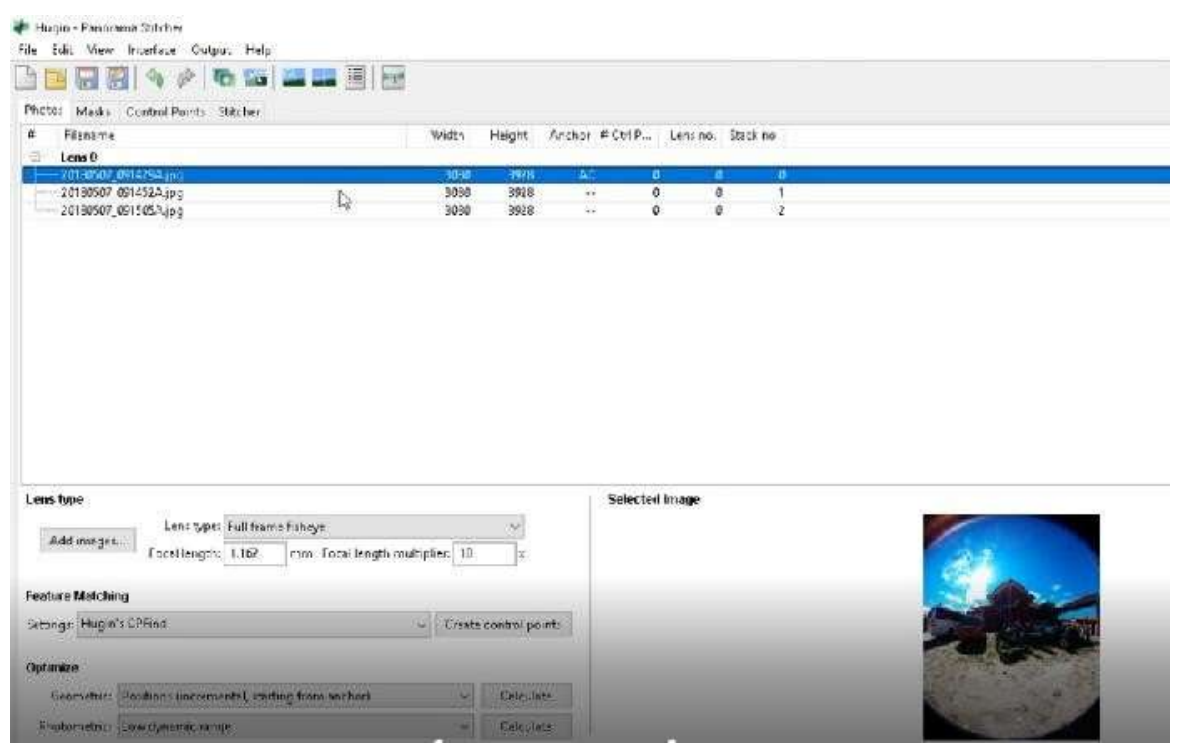

Gambar 4. Melakukan setting pada gambar-gambar yang telah dipotong (crop)

Pada gambar 4 merupakan proses memasukkan hasil gambar crop yang menggunakan photoshop kedalam hugin, yang harus diperhatikan bahwa semua gambar harus dimasukkan dalam sebuah lens dengan tipe lens full frame fisheye, focal length 1.16 serta focal length multiplier 18x. Kita tidak perlu melakukan settingan berulang-ulang saat memasukkan settingan gambar, cukup satu gambar pada rententan gambar yang ada maka seluruh setting gambar akan berubah.

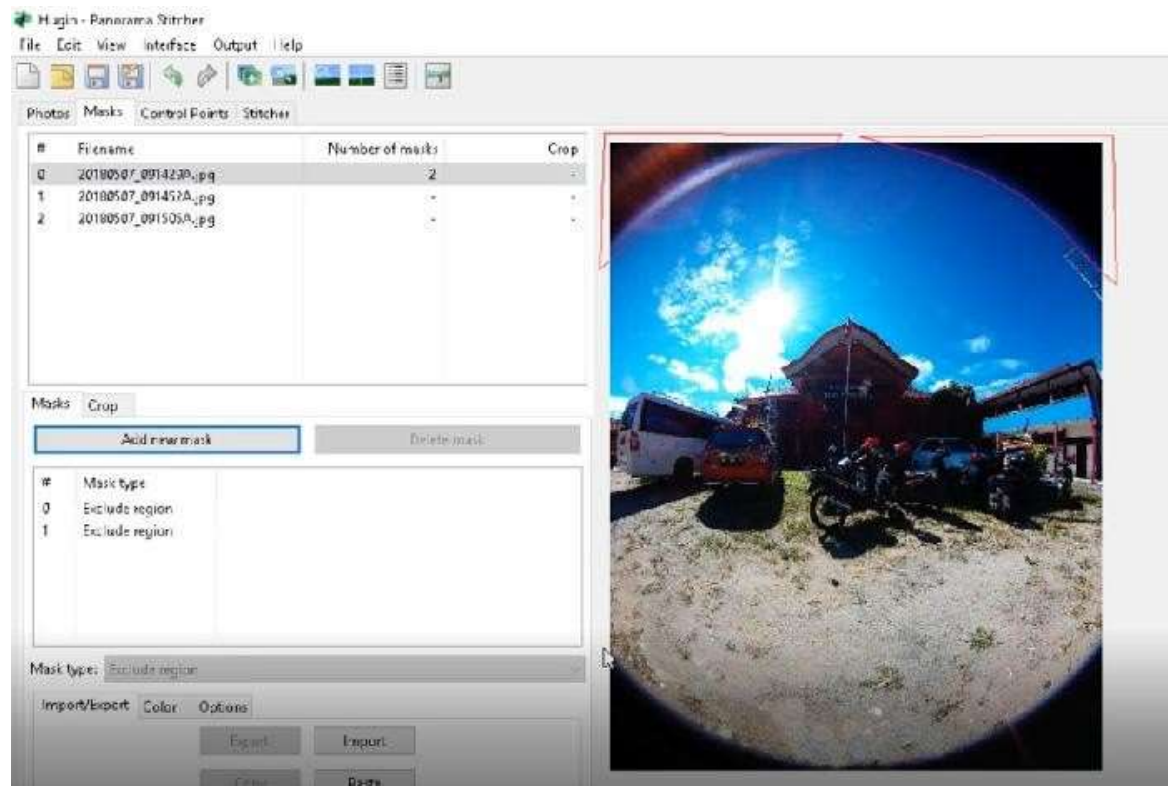

Gambar5. Proses mask

Pada gambar 5 dapat dilihat bahwa gambar memiliki ara hitam pada tiap sudut kiri atas/bawah, kanan atas/bawah. Sampai saat ini perangkat lunak hugin tidak dapat secara otomatis membuang bagian-bagian hitam tersebut, sehingga dibutuhkan campur tangan 
manusiadalammelakukannya.Kerenatiapgambarmemiliki4bagianhitammakamaskdilakukan sebanyak 4 kalijuga.

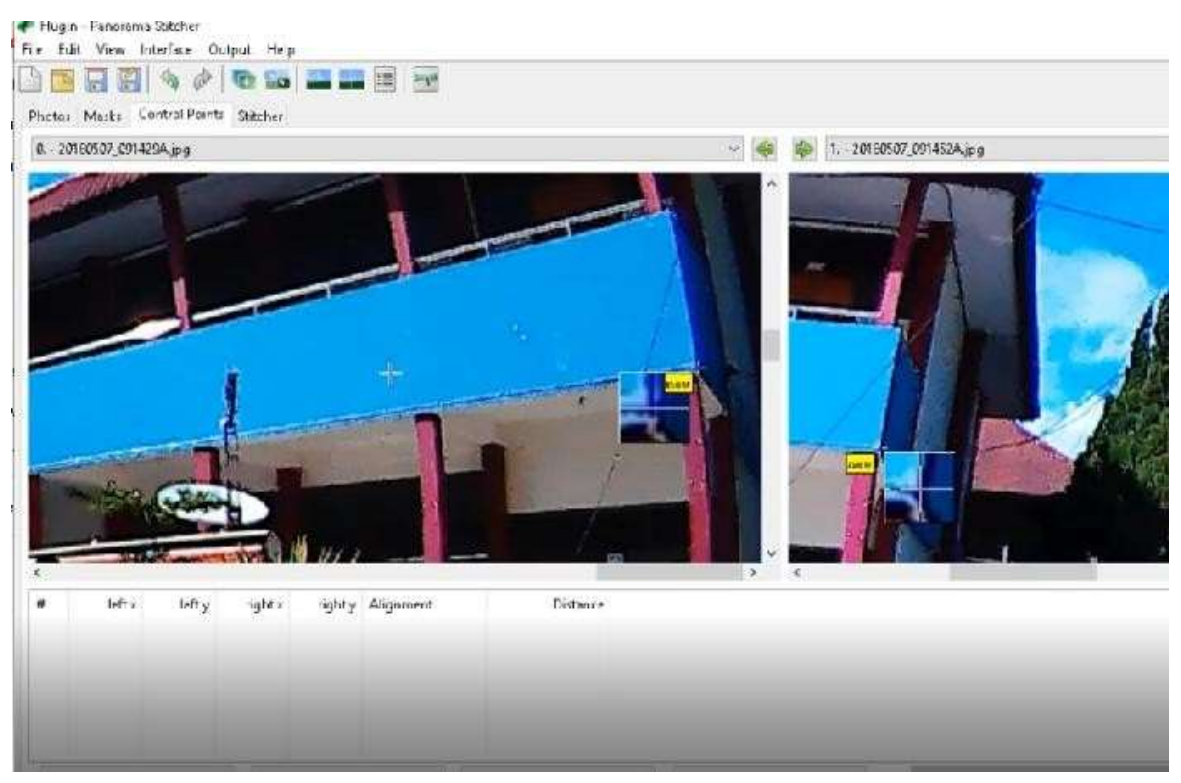

Gambar 6. Proses Control Point

Pada gambar 6 dapat dilihat bahwa gambar memiliki kesamaan objek-objek tertentu, hal ini disebabakan karena sudut pengambilan gambar pada kamera kogan adalah $220^{\circ}$ sedangkan pengambilan gambar dilakukan tiap $120^{\circ}$. Jadi ada persinggungan gambar satu dengan yang lain. Pada proses ini control point dilakukan dengan dengan mencari kesamaan antargambar, tetapi dalam hal ini Hugin sudah cukup baik dalam mencari titik-titik kesamaan gambar, sehingga kita tidak perlu banyak mencari kesamaan pada gambar-gambar tersebut.

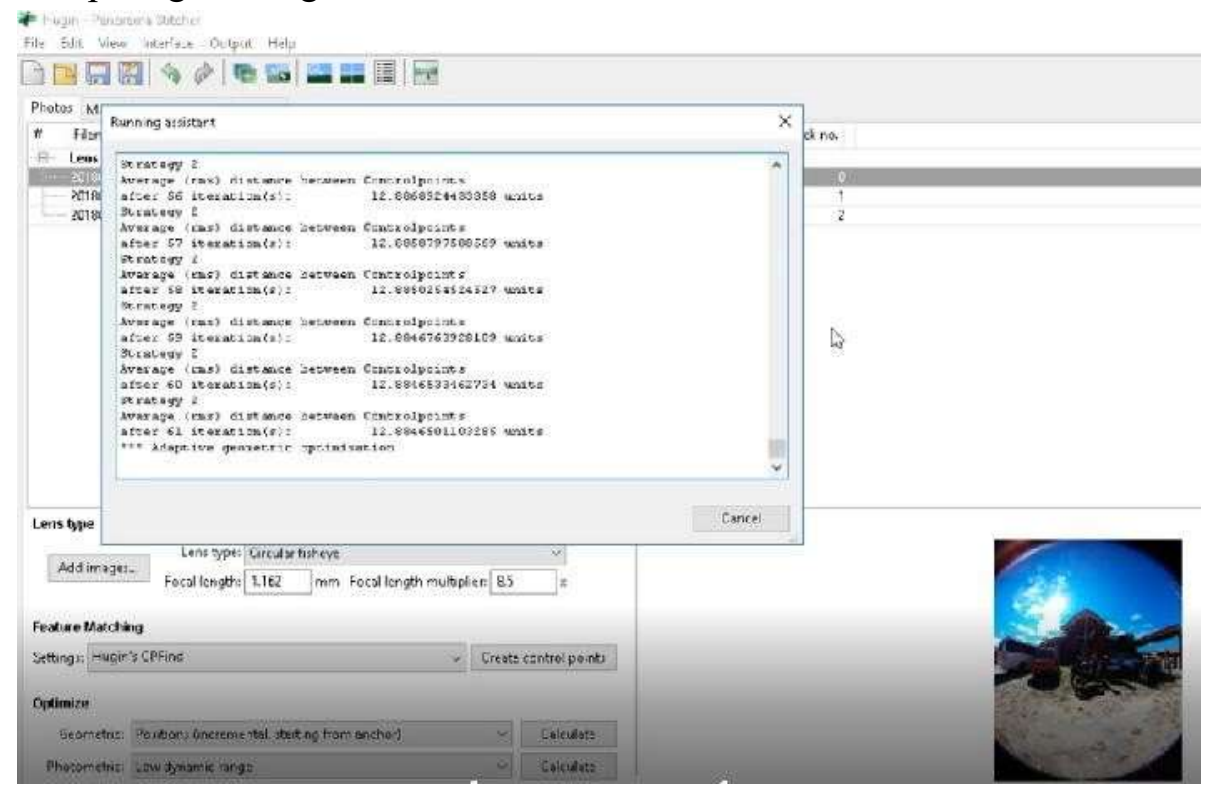




\section{Gambar 7. Proses Automasi}

Pada gambar 7 dapat dilihat bahwa Hugin memiliki kecerdasan buatan yang baik, jadi dalam melakukan sulaman gambar setelah proses-proses diatas tersebut bisa menghasilkan gambar yang menakjubkan.

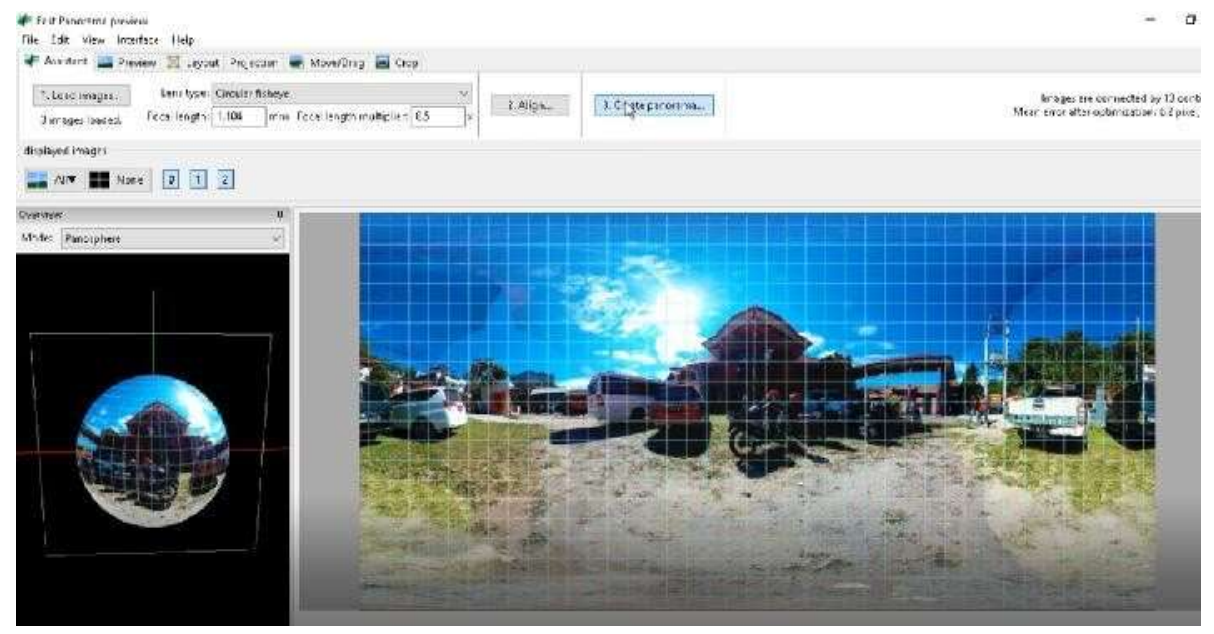

Gambar 8. HasilSementara

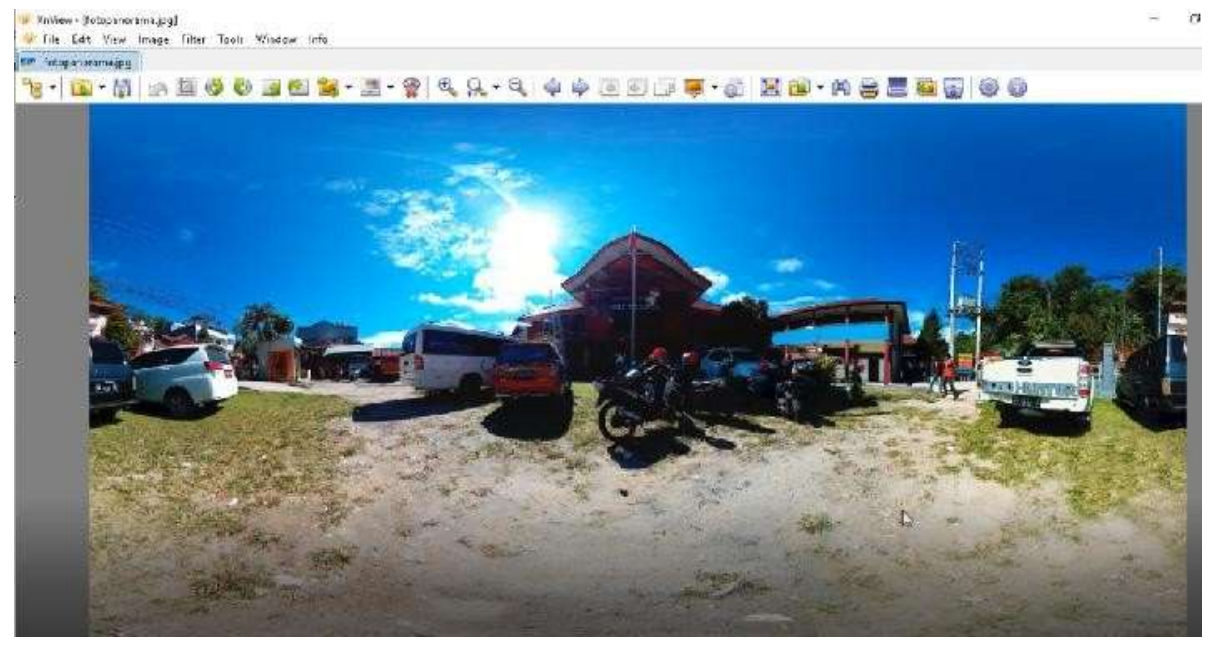

Gambar 9. Hasil akhir proses Hugin

Pada gambar 8 dan 9 adalah hasil gambar yang telah diproses oleh hugin. Gambarnya akan tampak seperti menggunakan kamera panorama. Tetapi pada meta jpg ada kode-kode sulam sehingga gambar akan secara otomatis berpindah jika kursor berada pada sudut-sudut atau ujungujung gambar. 


\section{KESIMPULAN DAN SARAN}

\section{Kesimpulan}

Dalam melakukan proses pengabdian ini, pengabdi telah melakukan sebaik dan sebisa yang dapat dilakukan. Tetapi pada akhirnya akan kembali kepada para mitra, apakah sistem yang dibangun akan digunakan sebaik-baiknya atau tidak. Proses pembelajaran tidak mudah karena kesibukan mitra dan kerumitan karena mitra belum menguasai penggunaan teknologi berbasis web.

\section{Saran}

Mitra harus berperan aktif dalam melakukan pengumpulan data dan informasi yang berguna bagi bisnisnya.

\section{DAFTAR PUSTAKA}

[1] Andy A.J, et al, 2016, “A Proposed Method for Predicting US Presidential Election by Analyzing Sentiment in Social Media", 2nd International Conference on Science in Information Technology.

[2] Baloian N, Gutierrez F, Zurita G, 2013, "An Architecture for Developing Distributed Collaborative Applications using HTML5," Computer Supported Cooperative Work in Design (CSCWD), 2013 IEEE 17th International Conference on. IEEE.

[3] David Sin, et al, 2012, "Mobile web apps - the non-programmer's alternative to native applications", 5th International Conference on Human System Interactions.

[4] Josefa G., et al, 2016, "Web-based Application to Obtain the Propagation in Outdoor Environments Importing Data from OpenStreetMaps", URSI International Symposium on Electromagnetic Theory (EMTS).

[5] Karl A, et al, 2012, "Mobile e-Services Using HTML5", 6th IEEE Workshop On User MObility and VEhicular Networks.

[6] Khan M.S., et al, 2016, "Virtual Community Detection through the Association between Prime Nodes in Online Social Networks and Its Application to Ranking Algorithms", IEEE Access.

[7] Mangkunegara, Anwar Prabu, 2004, "Manajemen Sumber Daya Manusia Perusahaan", Bandung: PT. Remaja Rosdakarya.

[8] Notoatmodjo, 2009, "Metodelogi Penelitian", PT. Rineka Cipta.

[9] Pengyu Du, et al, 2016, “A Real-Time Collaborative Framework for 3D Design based on HTML5", Proceedings of the 2016 IEEE 20th International Conference on Computer Supported Cooperative Work in Design.

[10] Reshma M, Raji R.P., 2016, "Semantic Based Trust Recommendation System for Social Networks using Virtual Groups”, 2016 International Conference on Next Generation Intelligent Systems (ICNGIS).

[11] Yu Sheng, at al, 2016, "A Virtual Laboratory Based on HTML5", The 11th International 
Conference on Computer Science \& Education (ICCSE 2016).

[12] Zhanlin J, et al, 2013, "The mServices GUI Architectures Design for the mLearning System", International Conference on Cyber-Enabled Distributed Computing and Knowledge Discovery. 